\title{
Effects of gender, age and treatment duration on lipid profile and renal function indices in diabetic patients attending a teaching hospital in South-Western Nigeria
}

\author{
Mary Alaba Aderibigbe, Tajudeen Olabisi Obafemi, Mary Tolulope Olaleye, Afolabi Clement Akinmoladun
}

Department of Biochemistry, School of Sciences, The Federal University of Technology, P.M.B. 704, Akure, Nigeria.

\begin{abstract}
Background: Type 2 Diabetes Mellitus (T2DM) is associated with diabetic nephropathy and hyperlipidemia. Gender, age, medication adherence, lifestyle, culture and socioeconomic status could be sources of diversity in T2DM leading to differences in predisposition, development and clinical presentation.

Objectives: Therefore, this study aimed to investigate the influence of gender, age and treatment duration on kidney and lipid-related biochemical indices of T2DM patients attending Ekiti State University Teaching Hospital, Ado-Ekiti, Nigeria (EKSUTH).

Methods: Blood from diabetic patients and healthy subjects was analysed for fasting blood glucose (FBG), renal function parameters and lipid profile. Influence of age, gender and treatment duration on indices was assessed using standard baseline values.

Results: Dyslipidemia was pronounced among female diabetics while the incidence of diabetes was found to be higher in middle-age. The percentage of diabetics with high levels of FPG, urea, creatinine, cholesterol, triglyceride and low density lipoprotein-cholesterol after 9-10 years of treatment were lower compared with the percentage after 5-6 years of treatment.

Conclusion: Gender, age and treatment duration influenced clinical course of T2DM among patients presenting at EKSUTH but long term treatment appeared to improve T2DM among patients.

Keywords: Fasting blood glucose, dyslipidemia, creatinine, atherogenic index, diabetes, Ekiti State.

DOI: https://dx.doi.org/10.4314/ahs.v18i4.8

Cite as: Aderibigbe MA, Obafemi TO, Olaleye MT, Akinmoladun AC. Effects of gender, age and treatment duration on lipid profile and renal function indices in diabetic patients attending a teaching hospital in South-Western Nigeria. Afri Health Sci. 2018;18(4): 900-908. https:// dx.doi. org/10.4314/ahs.v18i4.8
\end{abstract}

\section{Introduction}

Diabetes mellitus (DM) is estimated to affect $2.8 \%$ of the world's population at present and projected to cross

\section{Corresponding author: \\ Afolabi C. Akinmoladun, \\ Department of Biochemistry, \\ School of Sciences, \\ The Federal University of Technology, \\ PMB 704, Akure 340001, Nigeria. \\ Tel: +2348034445893. \\ E-mail: acakinmoladun@futa.edu.ng; \\ akinmoladunfc@yahoo.co.uk}

$5.4 \%$ mark by $2025^{1}$. The International Diabetes Federation (IDF) estimated that in 2011 there were 366 million people with diabetes and this was expected to rise to 552 million by $2030^{2}$. According to IDF atlas (2012) the prevalence rate of diabetes in Africa is $4.3 \%$, while $81.2 \%$ of cases remain undiagnosed. Africa has the highest mortality rate due to diabetes and over the next 20 years, the number of people with diabetes in Africa will almost double. Diabetes is considered a syndrome because of the many symptoms the individuals present with especially if management is not adhered to ${ }^{3,4}$. Lack of insulin or relatively low insulin levels affects the metabolism of carbohydrate, protein, fat, water and electrolyte balance resulting in diabetes ${ }^{5,6}$. The prevalence of T2DM increases with age such that in developing countries, most diabetics

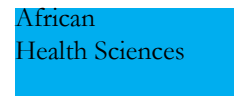

(C) 2018 Aderibigbe et al. Licensee African Health Sciences. This is an Open Access article distributed under the terms of the Creative commons Attribution License (https://creativecommons.org/licenses/BY/4.0), which permits unrestricted use, distribution, and reproduction in any medium, provided the original work is properly cited. 
are in the age group of 45 to 64 years, while in developed countries the largest number is found in those aged 65 years and above $\mathrm{e}^{7,8}$.

The major risk factors for T2DM are obesity $(>120 \%$ ideal body weight or a body mass index $>30 \mathrm{~kg} / \mathrm{m}^{2}$ ) and a sedentary lifestyle ${ }^{9,10}$. In T2DM lipid abnormalities are almost the rule. Typical findings are elevation of total and VLDL-C cholesterol, triglyceride concentration, lowering of HDL-C cholesterol and a predominance of small, dense LDL-C particles ${ }^{11}$. Insulin resistance is often involved in this process ${ }^{12}$ though the pathophysiology of lipid abnormalities in diabetes is not yet totally explained. Urea and creatinine levels are also affected in diabetes. During dehydration urea clearance is decreased and more is reabsorbed causing an increase in blood urea level. Urea and creatinine are the parameters to diagnose functioning of the kidney. However, changes in serum creatinine concentration more reliably reflect changes in glomerular filtration rate (GFR) than do changes in serum urea concentrations ${ }^{13}$.

There is no uniform view on the influence of age and gender on T2DM among researchers. It has been reported that T2DM is more frequently diagnosed at lower age and body mass index in men whereas the most prominent risk factor, which is obesity, is more common in women ${ }^{14}$. Another study associated the higher prevalence of T2DM in older men than in older women with larger amount of visceral fat in men ${ }^{15}$. However, a previous study showed that among Zuni Indians, the prevalence of diabetes was higher in females than males ${ }^{16}$. It has been observed that there is wide sex-ratio diversity in T2DM across countries leading to differences in predisposition, development and clinical presentation and, the differences between males and females could be influenced by culture, lifestyle and socioeconomic status ${ }^{14,16}$. Therefore, the objectives of this study were to determine the fasting blood glucose (FBG), lipid profile, urea and creatinine levels as well as derived cardiovascular risk factors in T2DM patients attending Ekiti State University Teaching Hospital, Ado-Ekiti, Nigeria (EKSUTH) and examine the effect of sex, age, and duration of treatment on the studied parameters. This could provide valuable insights that will assist health professionals in providing better treatment and help researchers in evolving more effective approaches in antidiabetic investigations.

\section{Subjects and methods}

\section{Experimental design and sample collection}

A total of 106 known T2DM and 40 normal subjects of both sexes, aged between 30 years and 90 years attending the medical outpatients department of EKSUTH were screened and used for the study. Ethical clearance for the study was approved by the ethical committee of EKSUTH (EKSUTH/A67/2013/01/03) and the research conformed to the World Medical Association declaration of Helsinki regarding ethical conduct of research involving human subjects and/or animals. Information from medical records was used to confirm the T2DM status of subjects. Informed consent was obtained from patients who participated in the study. Information on age, gender, cigarette smoking, duration of diabetes, socioeconomic status and family history of coronary heart disease was obtained through a questionnaire administered by interviewers. Patients who were very ill or on admission were excluded from the study. Patients with chronic diseases, history of cardiovascular incidents and using drugs for hypertension were also excluded from the study. The criteria for choosing controls was fasting blood glucose $\leq 7.0 \mathrm{mmol} / \mathrm{L}$ and systolic blood pressure values $\leq 140$ $\mathrm{mmHg}$.

Fasting venous blood sample was collected from each subject (both tests and controls) into fluoride oxalate containers (for glucose determination) and lithium heparin sample containers (for lipid profile, urea and creatinine determination). Each blood sample was mixed gently and spun as quickly as possible at $3000 \mathrm{rpm}$ for 5 min. Plasma was extracted into plain tubes and stored at $-4^{\circ} \mathrm{C}$ for further analyses. Fasting blood glucose, plasma urea, creatinine and lipid profile assay comprising of plasma triglycrides (TRIG), Total Cholesterol (CHOL), and High-density Lipoprotein cholesterol (HDL-C) were performed by methods based on enzymatic determination using kits obtained from Randox Laboratories Ltd. (United Kingdom). Low-density Lipoprotein cholesterol (LDL-C) was calculated from Friedewald formula. $\mathrm{CHOL}$ is a measure of the cholesterol components: LDL-C, HDL-C and Very Low-density Lipoprotein cholesterol (VLDL-C). Reference range for FPG and urea are 4.1$5.9 \mathrm{mmol} / \mathrm{L}$ and $2.1-7.1 \mathrm{mmol} / \mathrm{L}$, respectively ${ }^{17}$. The reference range for creatinine is $62-115 \mathrm{mmol} / \mathrm{L}$ for males and $53-97 \mathrm{mmol} / \mathrm{L}$ in females. ${ }^{17}$ Target levels $(\mathrm{mmol} / \mathrm{L})$ 
for CHOL, LDL-C, and TRIG are $<5.17,2.58$ and 1.69, respectively while the risk levels are $>6.20,4.13$ and 2.26, respectively. The reference range for HDL-C is 1.03-1.55 $\mathrm{mmol} / \mathrm{L}^{18}$. Dyslipidemia, which is a disorder of lipoprotein metabolism and a condition of an abnormal level and proportion of lipids in the blood, was assessed in subjects through comparison of lipid levels of patients with reference values. Derived cardiovascular risk factors such as the atherogenic index of plasma are predictive of the risk of atherosclerosis and coronary heart disease.

\section{Statistical analysis}

Statistical analysis of the data generated was performed with computer software, Statistical Package for Social Sci- ences (SPSS) version 16.0. Values were expressed as mean \pm standard deviation (SD). The data was analyzed using Analysis of variance (ANOVA) and Student's t-test. P < 0.05 was considered significant.

\section{Results}

Subjects in this study were of Yoruba ethnicity and a mixture of those who had formal education and those who did not. Most of the diabetic patients were on DM foods like beans, unripe plantain and fruits.

A significantly higher fasting blood glucose $(p<0.0001)$, creatinine $(p<0.0001)$ and urea $(p<0.0455)$ levels were observed in the diabetic group when compared with the controls (Figure 1).

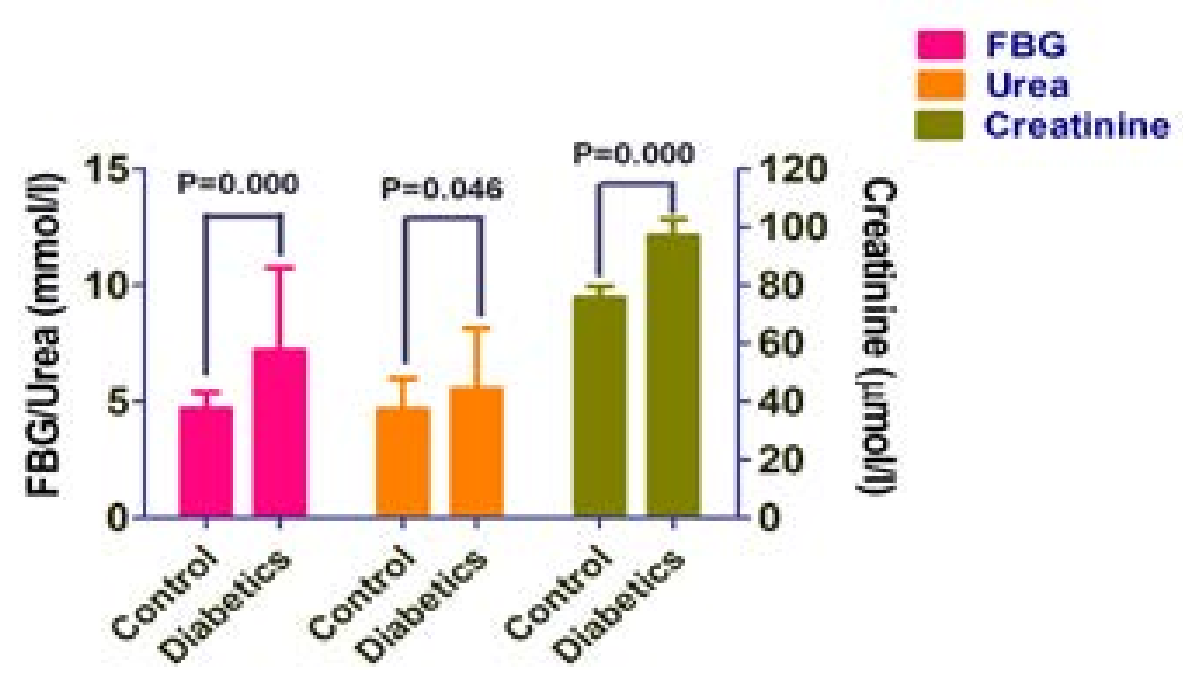

Figure 1. Fasting blood glucose, creatinine and urea levels in controls and diabetics. Results are presented as mean \pm SD $(n=40$ for control and 106 for diabetics). Diabetics showed significantly higher levels of the measured indices than the control subjects. FBG: Fasting blood glucose.

In addition, the diabetic group showed significantly higher TRIG $(p<0.0001)$ and LDL-C $(p<0.009)$ but lower
HDL-C $(\mathrm{p}<0.0001)$ levels compared with normal subjects (Figure 2). Cholesterol level in diabetics was also slightly higher than in control $(\mathrm{P}>0.05)$. 


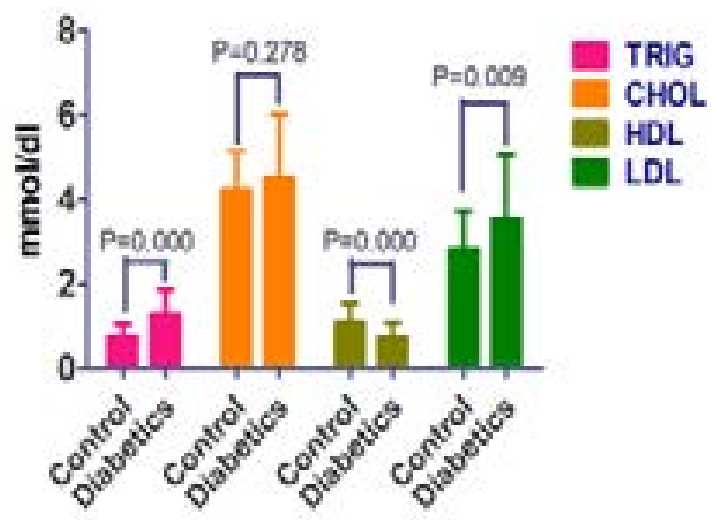

Figure 2. Lipid profile of control and diabetic groups. Results are presented as mean $\pm \mathrm{SD}$ ( $\mathrm{n}=40$ for control and 106 for diabetics).

Values for TRIG, HDL-C and LDL-C in diabetics were significantly different from those of controls. Diabetic CHOL was not significantly different from control.

TRIG: triglycerides; CHOL: total cholesterol; HDL-C: High-density lipoprotein cholesterol; LDL-C: Low-density lipoprotein cholesterol.

The derived cardiovascular risk factors are presented in Figure 3. CHOL/HDL-C, LDL-C/HDL-C, TRIG/ HDL-C and the atherogenic index of plasma (AIP) were all higher in diabetics compared to normal subjects. Cholesterol/HDL-C ratio, LDL-C/HDL-C ratio, TRIG/
HDL-C ratio and the atherogenic index of plasma for the diabetic group were $4.89 \pm 0.66,6.28 \pm 0.60,0.68 \pm 0.69$ and $0.25 \pm 0.24$, respectively compared with the corresponding values for the control group: $3.23 \pm 0.51,3.88 \pm 0.45$, $1.78 \pm .57$ and $-0.1682 \pm 0.16$, respectively $(\mathrm{P}<0.0001)$.

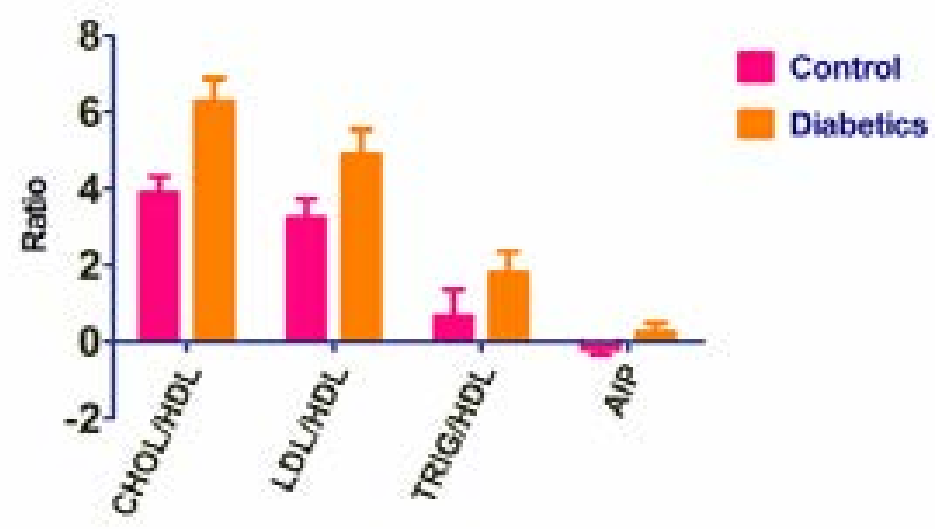

Figure 3. Derived predictors of cardiovascular risk. Results are presented as mean $\pm \mathrm{SD}(\mathrm{n}=40$ for control and 106 for diabetics). Values for diabetics are significantly different from corresponding control values for all indices $(\mathrm{P}<0.0001)$. CHOL: total cholesterol; HDL-C: High-density lipoprotein cholesterol; LDL-C: Low-density lipoprotein cholesterol; TRIG: triglycerides; AIP: atherogenic index of plasma.

Table 1 showed that among the measured indices in both control and diabetic groups, gender difference was observed only in CHOL and LDL-C levels in diabetics where significantly higher values $(\mathrm{P}<0.05)$ were recorded in females $(4.67 \pm 1.52 \mathrm{mmol} / \mathrm{dl}$ and $3.69 \pm 1.54 \mathrm{mmol} /$ dl) than in males $(3.99 \pm 1.32 \mathrm{mmol} / \mathrm{dl}$ and $2.96 \pm 1.36$ $\mathrm{mmol} / \mathrm{dl})$, respectively.

This implies that CHOL and LDL-C values were, respectively $19 \%$ and $25 \%$ higher in female diabetics when compared with male diabetics. 
Table 1. Effect of gender on parameters in diabetic and control groups

\begin{tabular}{lllllll}
\hline Parameters & $\begin{array}{l}\text { Controls } \\
\text { Male (14) }\end{array}$ & Female (26) & P. values & $\begin{array}{l}\text { Diabetics } \\
\text { Male (25) }\end{array}$ & Female (81) & P. Value \\
\hline FBG & $4.54 \pm 0.64$ & $4.75 \pm 0.16$ & 0.366 & $6.58 \pm 0.99$ & $7.3 \pm 1.02$ & 0.330 \\
Urea & $4.78 \pm 0.34$ & $4.59 \pm 0.3$ & 0.669 & $5.14 \pm 0.23$ & $5.65 \pm 0.33$ & 0.393 \\
Creatinine & $72.08 \pm 1.34$ & $77.34 \pm 1.40$ & 0.266 & $85.08 \pm 1.16$ & $100.73 \pm 2.29$ & 0.299 \\
Triglycerides & $0.79 \pm 0.09$ & $0.71 \pm 0.07$ & 0.435 & $1.15 \pm 0.06$ & $1.32 \pm 0.13$ & 0.213 \\
Cholesterol & $4.11 \pm 0.15$ & $4.32 \pm 0.11$ & 0.485 & $3.99 \pm 0.32$ & $4.67 \pm 0.52$ & 0.046 \\
HDL-C & $1.14 \pm 0.10$ & $1.07 \pm 0.05$ & 0.614 & $0.79 \pm 0.34$ & $0.69 \pm 0.07$ & 0.249 \\
LDL-C & $2.58 \pm 0.18$ & $2.98 \pm 0.16$ & 0.165 & $2.96 \pm 0.36$ & $3.69 \pm 0.54$ & 0.037 \\
& & & & & & \\
\hline
\end{tabular}

Values are presented as means $\pm \mathrm{SD}, \mathrm{n}$ is as shown in parenthesis. $\mathrm{P}<0.05$ implies significant difference between values for control or diabetics in a row.

Figure 4 shows the percentage of subjects in the diabetics group that presented with high levels of the measured parameters with respect to the reference values. The graph was plotted by making the subjects presenting with values higher than reference values for biochemical parameters in each age group a percentage of the total subjects in that age group.

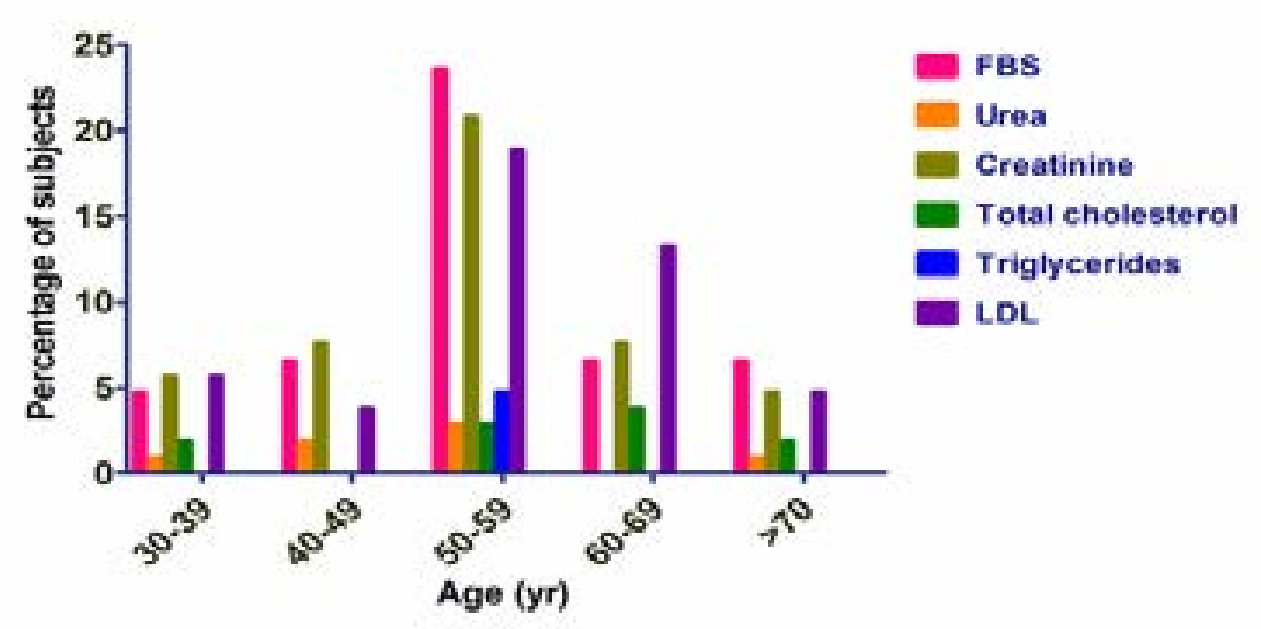

Figure 4. Percentage of diabetics showing high levels of measured parameters in various age groups. Highest percentage of diabetics with high levels of measured parameters was in the 50-59 year group. FBG: Fasting blood glucose; LDL-C: Low-density lipoprotein cholesterol.

We observed that the 50-59 age groups had the highest percentage of subjects that presented with high levels of most of the parameters evaluated in this study. The percentage of diabetics presenting with high levels of fast- ing blood glucose, urea, creatinine, CHOL, TRIG and LDL-C after $9-10$ years of treatment were $2 \%, 0 \%, 2 \%$, $0 \%, 0 \%$ and $2 \%$, respectively compared with $16 \%, 2 \%$, $14 \%, 5 \%, 1 \%$ and $16 \%$, respectively after $5-6$ years of treatment (Figure 5). 


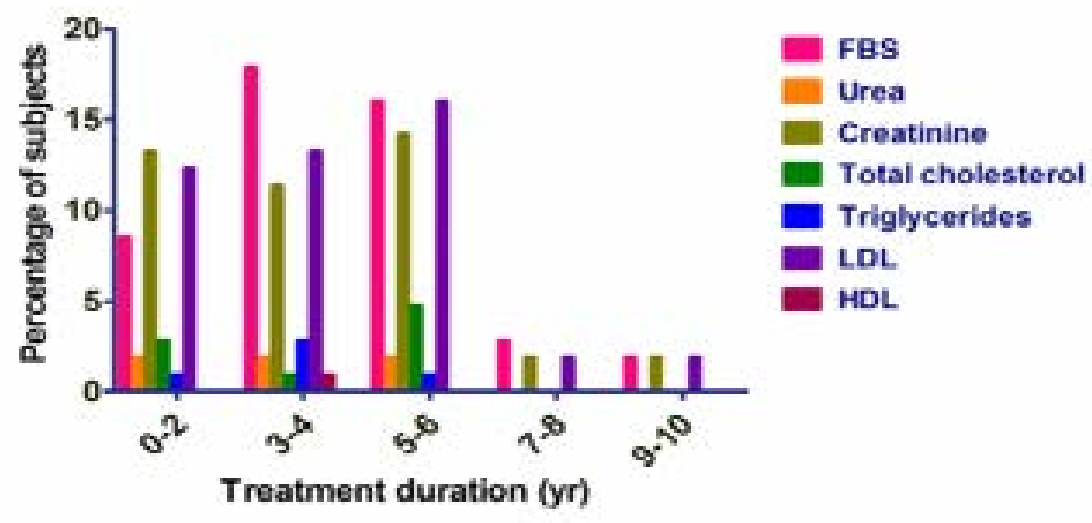

Figure 5. Percentage of diabetics presenting with high levels of measured parameters based on treatment duration. The percentage of diabetics with high levels of measured indices decreased after 5-6 years of treatment.

\section{Discussion}

The significantly higher plasma creatinine and urea levels in diabetics compared to controls are in agreement with previous findings which revealed the existence of a strong positive relationship between blood sugar level and urea level ${ }^{19-21}$. Plasma creatinine and urea are established markers of glomerular filtration with plasma creatinine being more sensitive index of kidney function. All renal cell types including glomerular podocytes, mesangial and endothelial cells, tubular epithelial cells, interstitial fibroblasts, and vascular endothelia may be affected by hyperglycaemic injury and this may explain the increase in urea and creatinine levels in the blood alongside chronic hyperglycemia $^{22-24}$. It has been reported that females with type 2 diabetes mellitus have a higher risk of renal dysfunction than males ${ }^{25,26}$. However, other studies reported a higher risk of renal dysfunction in type 2 diabetic males $^{25,27}$. In the present study, female diabetics were found to have higher urea and creatinine levels than their male counterparts, an indication that the female diabetics have poorer kidney function than the male diabetics. This inconsistency was ascribed to the background characteristics of participants in the studies ${ }^{28}$. The plasma glucose and creatinine levels of both male and female non-diabetics in our study was similar to an earlier study, however, the urea levels in the earlier study was significantly higher than the present study ${ }^{21}$.

Altered lipid profile is a feature of diabetes mellitus and dyslipidemia predisposes diabetic patients to cardiovascular complications, especially coronary heart disease $(\mathrm{CHD})^{29-31}$. The cause of the greater relative risk of $\mathrm{CHD}$ in diabetic women still remains incompletely understood. However, it has been reported that the adverse changes induced by T2DM in some cardiovascular risk factors, such as HDL-C, TRIG, LDL-C particle size and blood pressure have been found to be more pronounced in women than in $\operatorname{men}^{32,33}$. In the present study, a significantly $(p<0.05)$ higher levels of total cholesterol and LDL-C was observed in female diabetics when compared with their male counterparts. Moreover, a lower HDL-C level was also observed in diabetic females when compared with their male diabetics. These observations are in consonance with an earlier study ${ }^{34}$.

The LDL-C/HDL-C ratio and the CHOL/HDL-C ratio (atherogenic or Castelli index) are important components and indicators of vascular risk with greater predictive value than the isolated parameters used independently, particularly LDL-C ${ }^{35}$. In the Helsinki Heart Study, it was demonstrated that the LDL-C:HDL-C ratio paints the most relevant picture of a person's cardiovascular health risk especially when triglyceridaemia is taken into account and the risk is significantly higher in the presence of hypertriglyceridaemia ${ }^{36}$. In our study, diabetics had a higher $(\mathrm{P}<0.0001)$ LDL-C/HDL-C ratio when compared with the controls. According to previous workers, the risk level of LDL-C/HDL-C is $>3.5$ for men and $>3.0$ for women, while the target level for both men and women are 3.0 and 2.5, respectively in primary intervention. However, when there is no reliable calculation of LDL-C, especially when triglyceridaemia exceeds $300 \mathrm{mg} / \mathrm{dl}(3.36 \mathrm{mmol} / \mathrm{L})$, it is preferable to use the CHOL: HDL-C ratio. In the present study CHOL:HDL-C ratio of 6.28 and 3.88 were 
observed in diabetics and controls, respectively. A risk level 5.0 for men and 4.5 for women and a target level of 4.5 and 4.0 for men and women, respectively have been suggested ${ }^{37}$. The atherogenic index of plasma (AIP) represented as log (TG/HDL-C) has been successfully used as an additional index when assessing cardiovascular risk factors ${ }^{38,39}$. It has been suggested that AIP values of -0.3 to $0.1,0.1$ to 0.24 and above 0.24 are associated with low, medium and high cardiovascular risk, respectively ${ }^{40}$. Healthy controls in our study had an appreciably lower and safe AIP value as against the value shown by diabetics. Multiple epidemiological studies have shown that these ratios have a greater correlation with cardiovascular disease and are therefore better predictors of cardiovascular disease than simple lipid parameters ${ }^{41,42}$.

Our study shows that the 50-59 age group had the highest percentage of subjects that presented with derangements in most parameters evaluated in the study. This supports the generally known fact that the onset of T2DM is usually after 40 years although younger people are increasingly being diagnosed with diabetes. Fasting blood glucose, creatinine, urea, TRIG, and LDL-C levels were higher in majority of the subjects in this age group than others. This could imply that this age group is the period when most diabetics are first diagnosed as our result further showed that the percentage of subjects that showed high levels of these parameters in older age groups fell remarkably. This could be due to the fact that the older age groups have taken treatment for a relatively long time after being diagnosed with diabetes. This pattern is similar to the one observed in an earlier study where majority of the subjects in the diabetic group were in the age group of 50-59 years ${ }^{43}$. These results are in agreement with earlier works which showed that age plays a significant role in the risk of developing T2DM especially after 40 years ${ }^{44}$. However our result is at variance with Otamere et.a ${ }^{45}$ who reported that neither the age of the subjects nor the duration of the diabetes significantly affected the level of lipids. A similar lipid profile was observed between diabetics in our study and an earlier study, however, female diabetics in the present study had a higher triglyceride and LDL-C levels ${ }^{45}$.

The duration of treatment with anti-diabetic drugs had a significant effect on the studied parameters. In the present study, there was a marked decrease in the percentage of subjects showing high levels of fasting blood glucose, creatinine, urea, CHOL, LDL-C and triglyceride after receiving treatment for $\geq 7$ years when compared with those who have received treatment for less than 7 years. This showed the beneficial effect of long-term management (either through drugs and/or lifestyle modifications) of diabetics. Our observation is however in contrast with a previous study which reported an increase in serum creatinine and urea with duration of diabetes of more than 10 years with a higher percentage increase observed in females than males ${ }^{46}$.

Although there have been several studies in which biochemical indices were compared in normal and diabetic individuals, there is a dearth of studies in which all the parameters investigated in this study were compared and to the best of our knowledge, no similar study has been undertaken in Ekiti State, Nigeria.

This study indicated that more gender specific modalities for managing type 2 diabetes is desirable as female type 2 diabetes patients undergoing treatment at EKSUTH generally showed worse renal function and more deranged lipid profile than their male counterparts. While this study showed that dysregulated metabolic and lipid profiles are more prevalent in type 2 diabetics in the 50-59 age group, consistent management of the condition is necessary at all age groups, as long term management of the disease seems to be very beneficial.

\section{Limitations of the study}

This study was conducted in a tertiary health centre located in an urban environment. This explains why most of the subjects were relatively literate and are also aware of the importance of conventional medications for managing their conditions. In addition, the number of subjects could have been more and equal numbers of controls and diabetics, though desirable, were not used because the number of available patients that met the inclusion and exclusion criteria for diabetics and controls were different. It is however believed that better understanding of the effects of gender, age and treatment duration of type 2 diabetes would be more apparent if similar studies including more participants from sub-tertiary health centres are conducted over a wider area.

\section{Conflict of interest}

None declared. 


\section{References}

1.Patel DK, Prasad SK, Kumar R, Hemalatha S. An overview on antidiabetic medicinal plants having insulin mimetic property. Asian Pacific Journal of Tropical Biomedicine. 2012; 2 (4): 320-330

2. Whiting DR, Guariguata L, Weil C, Shaw J. IDF Diabetes Atlas: global estimates of the prevalence of diabetes for 2011 and 2030. Diabetes Research and Clinical Practice. 2011; 94 (3): 311-321

3. Stern M, Williams K, Gonzalez CV, Hunt KJ, Haffner $\mathrm{SM}$. Does the metabolic syndrome improve identification of individuals at risk of type 2 diabetes and/or cardiovascular disease? Diabetes care. 2004; 27 (11): 2676-2681

4. He X, Pan J, Pan M, Wang J, Dong J, Yuan H, et al. Dietary and physical activity of adult patients with type 2 diabetes in Zhejiang province of eastern China: Data from a cross-sectional study. Journal of Diabetes Investigation. 2016; 7 (4): 529-538.

5. Barroso I, Luan J, Middelberg RPS, Harding A, Franks PW, Jakes RW et al. Candidate gene association study in type 2 diabetes indicates a role for genes involved in b-cell function as well as insulin action. PLOS Biology. 2003; 1 (1): e20

6. Nagashima T, Shirakawa H, Nakagawa T, Kaneko S. Prevention of antipsychotic-induced hyperglycaemia by vitamin D: a data mining prediction followed by experimental exploration of the molecular mechanism. Scientific Reports. 2016; 6: 26375

7. Van Dam RM. The epidemiology of lifestyle and risk for type 2 diabetes. European Journal of Epidemiology. 2003; 18 (12): 1115 - 1125

8. Ikenna CE, Medea I, Ashish K, Arnold von E, Daiana S, Margaret WG et al. Air pollution and diabetes association: Modification by type 2 diabetes genetic risk score. Environment International. 2016; 94: 263-271

9. Shaw J, Chisholm D. Epidemiology and prevention of type 2 diabetes and the metabolic syndrome. The Medical Journal of Australia. 2003; 179 (7): 379 - 383

10. Wild S, Roglic G, Green A, Sicree R, King H. Global prevalence of diabetes; Estimates for the year 2000 and projections for 2030. Diabetes Care. 2004; 27 (5): 10471053

11. American Diabetes Association. Standards of medical care in diabetes. Diabetes Care. 2007; 30 (Suppl 1): S4S41

12. Joshua A, Becham B, Libby P. Diabetes and atherosclerosis: epidemiology, pathophysiology, and manage- ment. Journal of the American Medical Association. 2002; 287 (19): 2570-2581

13. Anupriya S, Hirulkar NB, Priyanka W, Prakash D. Influence of hyperglycemia on renal function parameters in patients with diabetes mellitus. International Journal of Pharmaceutical and Biological Archives. 2011; 2 (2):734-739

14. Kautzky-Willer A, Harreiter J, Pacini G. Sex and Gender Differences in Risk, Pathophysiology and Complications of Type 2 diabetes Mellitus. Endocrine Reviews. .2016; 37 (3): 276-316. PubMed

15. Nordstrom A, Hadrevi J, Olsson T, Franks PW, Nordstrom P. Higher Prevalence of Type 2 Diabetes in Men Than in Women Is Associated With Differences in Visceral Fat Mass. Journal of Clinical Endocrinology and Metabolism. 2016; 101(10): 3740-3746

16. Scavini M, Stidley CA, Shah VO, Narva AS, Tentori F, Kessler DS et al. Prevalence of Diabetes is Higher Among Female Than Male Zuni Indians. Diabetes Care. 2003; 26 (1): 55-60

17. Show-Hong D, Janine DC. (2005). Laboratory reference range values, University of Maryland School of Medicine. 96-112.

18. WHO. (2006). Guidelines for the prevention, management and care of diabetes mellitus. World Health Organization Regional Office for the Eastern Mediterranean. Technical Publications Series. No. 32.

19. Blessing OI, Oloruntoba F, Olarewaju MO. Plasma glucose, creatinine and urea levels in type II diabetic patients attending a Nigerian teaching hospital. Research Journal of Medical Sciences. 2011; 5 (1): 1-3

20. Adler AI, Stevens RJ, Manley SE, Bilous RW, Cull CA, Holman RR. Development and progression of nephropathy in type 2 diabetes: The United Kingdom Prospective Diabetes Study (UKPDS 64). Kidney International. 2003; 63 (1): 225-232

21. Wagle TJ. Gender-wise comparison of serum creatinine and blood sugar levels in type 2 diabetic patients. Bombay Hospital Journal. 2010; 52 (1): 36-40

22. Deepa K, Manjunatha GBK, Oinam SD, Devaki RN, Bhavna N, Asha P et al. Serum urea, creatinine in relation to fasting blood glucose levels in type 2 diabeticpatients. International Journal of Pharmacy and Biological Sciences. 2011; 1 (3): 279-283

23. Khaki A, Fathiazad F. Diabetic Nephropathy - Using herbals in diabetic nephropathy prevention and treatment - The Role of Ginger (Zingiber officinale) and Onion (Allium cepa) in Diabetic Nephropathy, A Compendium 
of Essays on Alternative Therapy. Bhattacharya $A$ (Ed), InTech, DOI: 10.5772/34953; 2012

24. Kanwar YS, Wada J, Sun L, Xie P, Wallner EI, Chen S, Chugh S, Danesh FR. Diabetic nephropathy: mechanisms of renal disease progression. Experimental Biology and Medicine. 2008; 233 (1): 4-11

25. Maric C, Sullivan S. Estrogens and the diabetic kidney. Gender Medicine 2008; 5 (Supplement 1): S103-S113

26. Yu MK, Lyles CR, Bent-Shaw LA, YoungBA. Risk factor, age and sex differences in chronic kidney disease prevalence in a diabetic cohort: the pathways study and the pathways authors. American Journal of Nephrology. 2012; 36 (3): 245-251

27. de Hauteclocque A, Ragot S, Slaoui Y, Gand E, Miot A, Sosner $\mathrm{P}$ et al. The influence of sex on renal function decline in people with Type 2 diabetes. Diabetic Medicine. 2014; 31 (9): 1121-1128

28. Kajiwara A, Kita A, Saruwatari J, Miyazaki H, Kawata Y, Morita K et al. Sex Differences in the Renal Function Decline of Patients with Type 2 Diabetes. Journal of Diabetes Research. 2016; 2016: Article ID 4626382

29. Muna WF. Cardiovascular disorders in Africa. World Health Statistics Quaterly. 1993; 46 (2): 125-133

30. Nakhjavani M, Esteghamati AR, Esfahanian F, Heshmat AR. Dyslipidemia in type 2 Diabetes mellitus: More atherognenic lipid profile in women. Acta Medica Iranica. 2006; 44 (2): 111-118. PubMed

31. Barrett-Connor E, Wingard DL. Sex differential in ischemic heart disease mortality in diabetics: a prospective population-based study. American Journal of Epidemiology. 1983; 118 (4): 489-496

32. Howard BV, Cowan LD, Go O, Welty TK, Robbins DC, Lee ET. Adverse effects of diabetes on multiple cardiovascular disease risk factors in women. The Strong Heart Study. Diabetes Care. 1998; 21 (8): 1258-1265. PubMed

33. Walden CE, Knopp RH, Wahl PW, Beach KW, Strandness E Jr. Sex differences in the effect of diabetes mellitus on lipoprotein triglyceride and cholesterol concentrations. New England Journal of Medicine. 1984; 311 (15): 953-959

34. Sapna S, Alok, ML. A Study on lipid profile levels of diabetics and non-Diabetics among Naini Region of Allahabad, India. Turkish Journal of Biochemistry. 2008; 33 (4): 138-141

35. Milan J, Pinto X, Munoz A, Zuniga M, Rubies-Prat J, Pallardo FL et al. Lipoprotein ratios: Physiological signifi- cance and clinical usefulness in cardiovascular prevention. Vascular Health and RiskManagement. 2009; 5: 757-765

36. Manninen V, Tenkanen L, Koskinen P, Huttunen JK, Mänttäri M, Heinonen OP, Frick MH. Joint effects of serum triglyceride LDL-C cholesterol and HDL-C cholesterol concentrations on coronary heart disease risk in the Helsinki Heart Study. Implications for treatment. Circulation. 1992; 85 (1): 37-45. PubMed

37. Kinosian B, Glick H, Garland G. Cholesterol and coronary heart disease: predicting risks by levels and ratios. Annals of Internal Medicine. 1994; 121 (9): 641-647

38. Dobiasova M, Frohlich J. The plasma parameter log (TG/HDL-C-C) as an atherogenic index: correlation with lipoprotein particle size and esterification rate in apo B- lipoprotein-depleted plasma. (FERHDL-C). Clinical Biochemistry. 2001; 34 (7): 583-588

39. Tan MH, Johns D, Glazer NB. Pioglitazone reduces atherogenic index of plasma in patients with type 2 diabetes. Clinical Chemistry. 2004; 50 (7): 1184-88. PubMed

40. Dobiasova M. AIP-atherogenic index of plasma as a significant predictor of cardiovascular risk: from research to practice. Vnitrní lékearství. 2006; 52 (1): 64-71. PubMed 41. Stampfer MJ, Krauss RM, Ma J, Blanche PJ, Holl LG, Sacks FM, Hennekens CH. A prospective study of triglyceride level, low-density lipoprotein particle diameter, and risk of myocardial infarction. Journal of the American Medical Association. 1996; 276 (11): 882-888

42. Ridker PM, Stampfer MJ, Rifai N. Novel risk factors for systemic atherosclerosis: a comparison of C-reactive protein, fibrinogen, homocysteine, lipoprotein(a), and standard cholesterol screening as predictors of peripheral arterial disease. Journal of the American Medical Association. 2001; 285 (19): 2481-2485

43. Daniel NA, Philip A. Type 2 diabetes mellitus influences lipid profile of diabetic patients. Annals of Biological Research. 2013; 4 (6): 88-92

44. Mayo Clinic. Type 2 diabetes. http://www.mayoclinic.org/diseases-conditions/type-2-diabetes/basics / risk-factors/con-20031902. Accessed January 12, 2015

45. Otamere HO, Aloamaka CP, Okokhere PO, Adisa WA. Lipid Profile in Diabetes Mellitus; What impact has age and duration. British Journal of Pharmacology and Toxicology. 2011; 2 (3): 135-137

46. Jiji I, Vijayalakshmy R. Role of Duration of Diabetes in The Development of Nephropathy In Type 2 Diabetic Patients. National Journal of Medical Research. 2013; 3 (1): $5-8$ 